\title{
Synergistic Anti-proliferative Effects of Lenalidomide and Dexamethasone on the HT-29 Cell Line Through Apoptotic Genes
}

\author{
Pantea Hajimirza Shafiesoltani (iD ${ }^{1}$, Flora Forouzesh (iD) ${ }^{1,}$, Mahdi Shabani (iD) ${ }^{2}$ and Mahmoud Aghaei (iD) ${ }^{3}$ \\ ${ }^{1}$ Department of Genetics, Faculty of Advanced Science and Technology, Tehran Medical Sciences, Islamic Azad University, Tehran, Iran \\ ${ }^{2}$ Department of Immunology, School of Medicine, Shahid Beheshti University of Medical Sciences, Tehran, Iran \\ ${ }^{3}$ Department of Clinical Biochemistry, School of Pharmacy \& Pharmaceutical Sciences, Isfahan University of Medical Sciences, Isfahan, Iran \\ "Corresponding author: Faculty of Advanced Science and Technology, Tehran Medical Sciences, Islamic Azad University, Dr Sharyati Street, Shahid Khaghani Street, P.O. Box: \\ 193951495, Tehran, Iran. Tel: +98-2122006660-7, Fax: +98-2122600714, Email: f8forouzesh@gmail.com
}

Received 2020 February 15; Revised 2021 June 07; Accepted 2021 June 07.

\begin{abstract}
Background: Colorectal cancer (CRC) is the third most common cancer among men and the second most common type of cancer among women worldwide. The resistance of tumor cells to apoptosis is caused by changes in the expression of anti-apoptotic or pro-apoptotic proteins. Histone deacetylase inhibitors (HDACi) are known to cause changes in gene expression.

Objectives: The present study aimed at investigating the anti-proliferative effects of lenalidomide (LEN) as HDACi and dexamethasone (DEX) on the human colon cancer HT-29 cell line.

Methods: The HT-29 cell line was treated with various concentrations of LEN and DEX individually and in combination for 24,48 , and 72 hours. Cytotoxicity was evaluated by MTT assay. The half-maximal inhibitory concentration ( $\mathrm{IC}_{50}$ ) was measured, and quantitative real-time polymerase chain reaction (qRT-PCR) was also performed to examine the expression of Bcl2, Bax, Fas, and FasL genes.

Results: The combination of $\operatorname{LEN}(1000 \mu \mathrm{M})$ with $\operatorname{DEX}(100 \mu \mathrm{M})$ showed potent synergistic anti-proliferative activities in a time- and dose-dependent manner. The combination of these drugs induced cell death by affecting the extrinsic and intrinsic apoptotic gene expression profiles.
\end{abstract}

Conclusions: The combination of LEN with DEX can be proposed as a new therapeutic approach for CRC.

Keywords: Colorectal Cancer, Apoptotic Genes, Lenalidomide, Dexamethasone, HT-29 Cell Line

\section{Background}

Colorectal cancer (CRC) is one of the most common causes of cancer-related death around the world (1). The global burden of CRC is predicted to increase by $60 \%$ (more than 2.2 million new cases) and cause 1.1 million deaths by 2030 (2). The American Cancer Society (ACS) used agespecific CRC screening to develop screening by race and sex and proposed a model to include changes in the US CRC incidence. The results of screening showed a significant reduction in CRC incidence (3).

During CRC development, the balance between cell growth and apoptosis, which maintains the intestinal epithelial cell homeostasis, is progressively disturbed (4). Disturbances in the balance between pro- and antiapoptotic pathways are associated with increased carcinogenesis (5). Cancer cells are usually more prone to apoptotic mechanisms compared to normal cells; this characteristic is probably the most widely used therapeutic indicator of cancer chemotherapy (6). Generally, tumor cells resistance to apoptosis is caused by the expression of antiapoptotic proteins or downregulation/mutation of proapoptotic proteins. The evasion of immune surveillance is another mechanism in cancer cells (7). Also, it is known that some tumor cells reduce the response of Fas to Fas receptors (FasL), which are produced by T cells to avoid immune destruction (8).

In cancer cells, the balance between histone transacetylase (HAT) and histone deacetylases (HDACs) is often disturbed, leading to changes in the expression of proto-oncogenes or tumor suppressor genes (9). The HDAC inhibitors (HDACi) induce apoptosis in tumor cells by regulating the expression of pro-apoptotic and antiapoptotic genes (10). Lenalidomide (LEN) is an analog of thalidomide (11) with HDACi activities (12). However, it was withdrawn from the market in 1961 because of its teratogenic effects (13). Thalidomide analogs were synthesized by reducing toxicity to optimize their anti-tumor necrosis factor-alpha (TNF- $\alpha$ ) and anti-angiogenic properties (11). 
LEN directly induces cell growth inhibition and apoptosis (14). Clinically, this medication has shown anti-tumor activity in patients with refractory multiple myeloma and/or relapse. In 2006, Food and Drug Administration (FDA) approved the combination of LEN with dexamethasone (DEX).

\section{Objectives}

The aim of the present study was to investigate the effects of LEN (HDACi) and DEX, both individually and in combination, on the extrinsic and intrinsic apoptotic gene expression profiles in the colorectal cancer HT-29 cell line.

\section{Methods}

\subsection{Cell Culture}

The human colorectal cancer HT-29 cell line was purchased from the Iranian Biological Resource Center (Tehran, Iran). The cells were grown in RPMI-1640 medium (Gibco, UK), supplemented with 10\% fetal bovine serum (FBS; Gibco, UK) and 1\% penicillin-streptomycin (Dacell, Iran). The cells were cultured at $37^{\circ} \mathrm{C}$ in a humidified $5 \%$ $\mathrm{CO}_{2}$ atmosphere.

\subsection{Preparation of LEN and DEX}

LEN (Santa Cruz Biotechnology, USA) was prepared in dimethyl sulfoxide (DMSO) and diluted in a culture medium immediately before use. The final concentration of DMSO in all experiments was $1 \%$. All treatment conditions were compared with the control group (untreated cells). In this study, a stock solution of DEX ( $4 \mathrm{mg} / \mathrm{mL}$ ) (Aburaihan Co., Iran) was diluted in a culture medium immediately before use.

\subsection{Cytotoxicity Assay}

The cells were individually treated with various concentrations of LEN (from 0.1 to $2000 \mu \mathrm{M}$ ) and DEX (from 0.1 to $1000 \mu \mathrm{M}$ ) and in combination for 24,48 , and 72 hours. Cell viability was also estimated by MTT assay (Sigma, USA). The half-maximal inhibitory concentration $\left(\mathrm{IC}_{50}\right)$ was calculated using the following formula:

$$
\begin{aligned}
\text { Cell viability rate }(\%)= & \frac{\left(O D_{\frac{570}{630}} \text { of treated cells }\right)}{\left(O D_{\frac{570}{630}} \text { of control cells }\right)} \\
& \times 100 \%
\end{aligned}
$$

\subsection{RNA Preparation and cDNA Synthesis}

According to the instructions of the manufacturer, total RNA was extracted from the treated and control cells using the RNX-Plus Solution (Sinaclon, Iran). For the removal of genomic DNA from RNA samples, a DNase treatment was used. RNA (2000 ng) was used to synthesize cDNA using a cDNA synthesis kit (Yekta Tajhiz, Iran).

3.5. Quantitative Real-Time Polymerase Chain Reaction (qRTPCR)

The qRT-PCR assay was performed for Fas, FasL, Bax, and $B c l 2$ genes, while the GAPDH gene was used as an internal control, using the SYBER green method in a Rotor-Gene 6000 RT PCR machine (Corbett, Australia). Table 1 presents the primer sequences in qRT-PCR. The primers were mainly designed from a specific exon-exon junction; we also made sure that DNA would not be amplified. The cycling conditions for amplifying all genes were as follows: at $95^{\circ} \mathrm{C}$ for 15 minutes, followed by 40 cycles of denaturation at $95^{\circ} \mathrm{C}$ for 15 seconds, annealing, and extension at $60^{\circ} \mathrm{C}$ for $60 \mathrm{sec}-$ onds. The relative mRNA expression levels were calculated using the comparative Ct method $\left(2^{\Delta \Delta \mathrm{Ct}}\right)$. Electrophoresis of the PCR products was also performed using an agarose gel.

\subsection{Statistical Analysis}

All experiments were performed in triplicate. A oneway ANOVA test was used for data analysis, and P-value less than 0.05 was considered statistically significant.

\section{Results}

4.1. Anti-proliferative Effects of LEN and DEX on the HT-29 Cell Line

Figure 1A shows that the viability of treated HT-29 cells did not significantly decrease at any concentration of LEN (from 0.1 to $2000 \mu \mathrm{M}$ ) as compared to the control group (untreated cells). Also, the viability of cells treated with different concentrations of DEX (from 0.1 to $1000 \mu \mathrm{M}$ ) was significantly reduced in a dose- and time-dependent manner as compared to the control group $(\mathrm{P}<0.05)$. The $\mathrm{IC}_{50}$ of DEX was $1000 \mu \mathrm{M}$ after 48 hours of treatment (Figure $1 \mathrm{~B}$ ).

\footnotetext{
4.2. Anti-proliferative Effects of LEN in Combination with DEX on the HT-29 Cell Line

The cytotoxic effect of LEN was more significant than LEN and DEX individually. DEX synergized with LEN to trigger the apoptosis of HT-29 cells. Treating HT-29 cells with a combination of LEN and DEX (1000 $\mu \mathrm{M}$ of LEN plus $1000 \mu \mathrm{M}$ of DEX) diminished the cell viability by $35 \%$ for 48 hours (Figure 2).
} 


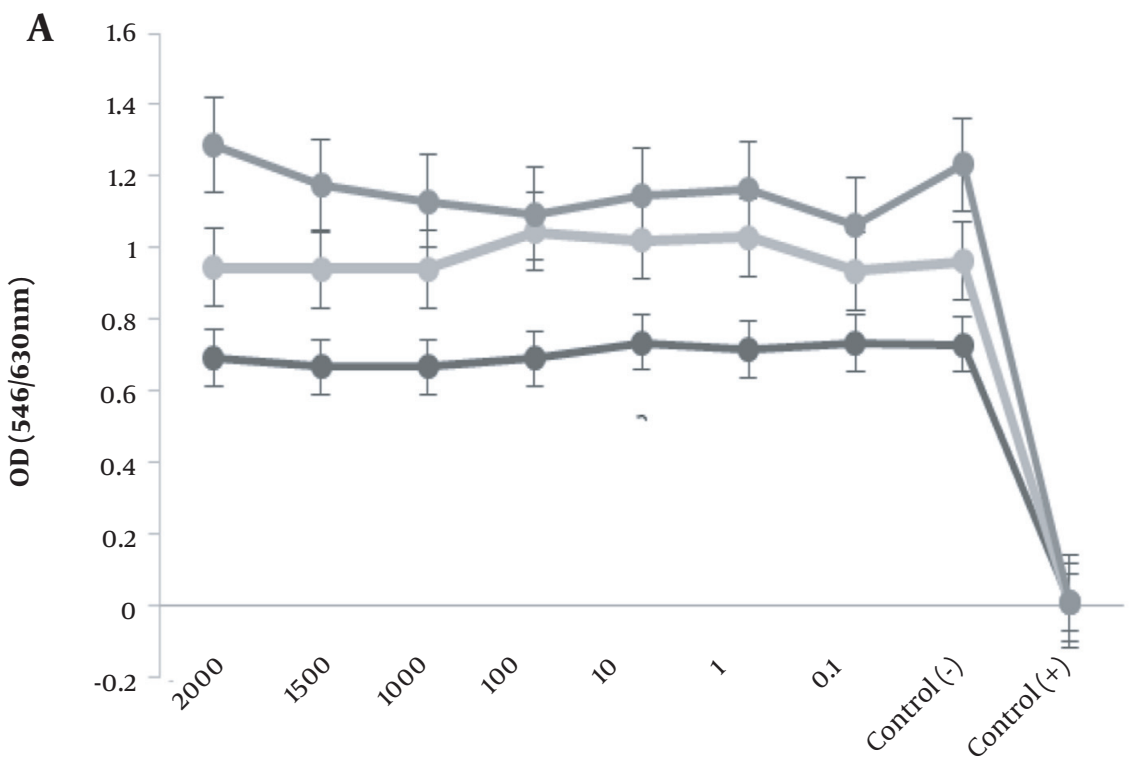

LEN Concentration $(\mu \mathrm{M})$

B

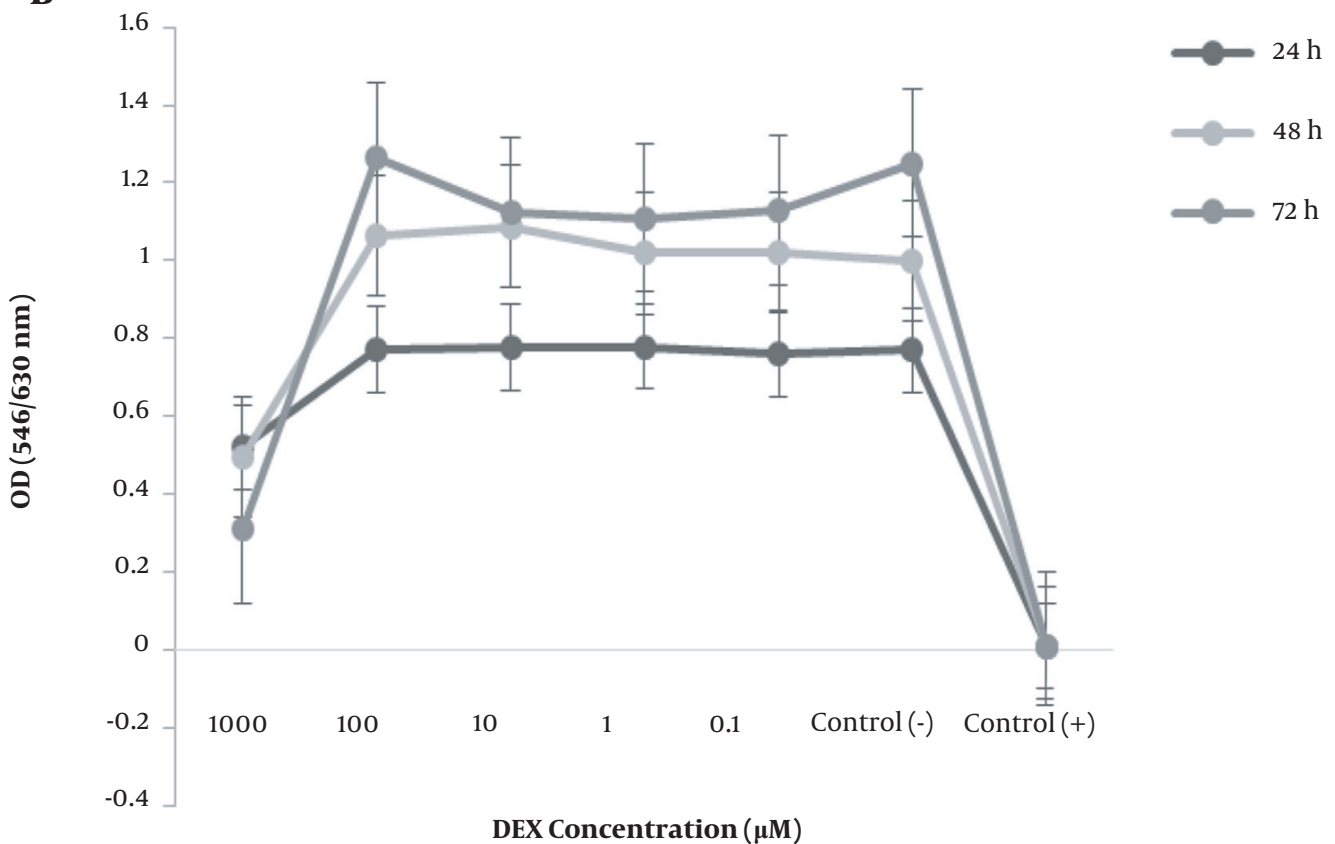

Figure 1. The anti-proliferative effects of LEN and DEX on the human colorectal cancer cell line. (A) The HT-29 cells were treated with different concentrations of LEN (from 0.1 to $2000 \mu \mathrm{M}$ ) for 24,48 , and 72 hours. (B) The HT-29 cells were treated with different concentrations of DEX (from 0.1 to $1000 \mu \mathrm{M}$ ) for 24,48 , and 72 hours. Cell viability was determined by MTT assay. Control (+): Cells treated with DMSO $20 \%$ as positive controls. Control (-): Untreated cells as negative controls. All experiments were performed in triplicate. 


\begin{tabular}{lrr}
\hline Table 1. Primer Sequences for Detecting Target Gene Expression by qRT-PCR & \\
\hline Name of Genes & Forward Primer Sequence $\left(\mathbf{5}^{\prime}-\mathbf{3}^{\prime}\right)$ & Reverse Primer Sequence $\left(\mathbf{5}^{\prime}-\mathbf{3}^{\prime}\right)$ \\
\hline $\boldsymbol{G A P D H}$ & GAAGGTGAAGGTCGGAGTC & GAAGATGGTGATGGGATTTC \\
$\boldsymbol{F a s}$ & TGCCAAGAAGGGAAGGAGTA & CGGGTGCAGTTTATTTCCAC \\
$\boldsymbol{F a s \boldsymbol { L }}$ & AGCAAATAGGCCACCCCAGTCC & TGGCTCAGGGGCAGGTTGTTG \\
$\boldsymbol{B a \boldsymbol { x }}$ & AACATGGAGCTGCAGAGGAT & CAGTTGAAGTTGCCGTCAGA \\
$\boldsymbol{B c l - 2}$ & ATGTGTGTGGAGAGCGTCAA & TCTTCAGAGACAGCCAGGAGA \\
\hline
\end{tabular}

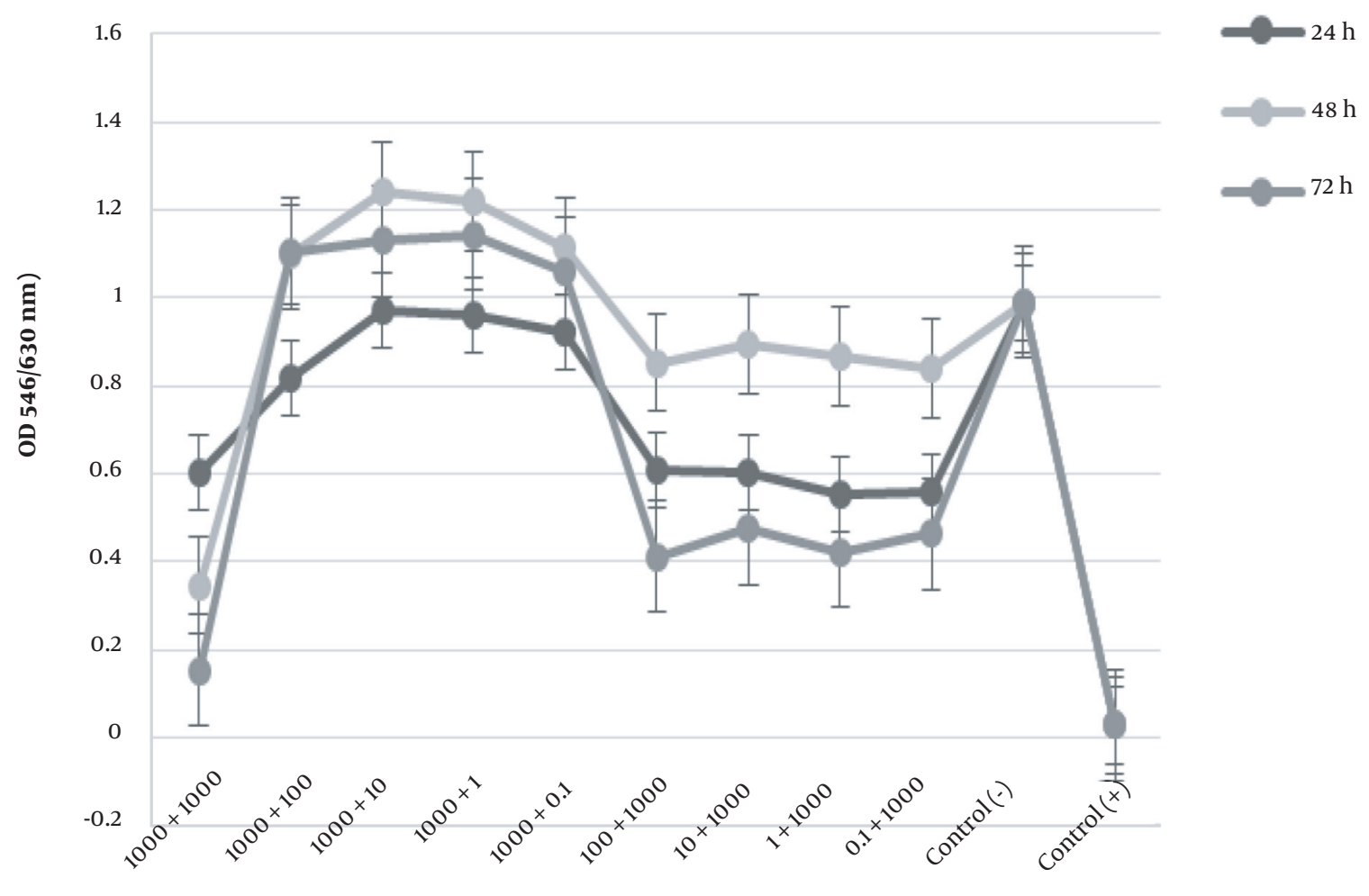

LEN + DEX Concentration $(\mu \mathrm{M})$

Figure 2. The anti-proliferative effect of LEN and DEX in combination on the human colorectal cancer cell line. The HT-29 cells were treated with different concentrations of LEN in combination with different concentrations of DEX for 24,48 , and 72 hours. Cell viability was measured by MTT assay. Control (+): Cells treated with DMSO $20 \%$ as positive controls. Control (-): Untreated cells as negative controls. All experiments were performed in triplicate.

4.3. Effects of LEN and DEX Individually and in Combination on the Extrinsic and Intrinsic Apoptotic Gene Expression Profiles

\subsubsection{Fas and FasL Genes}

In the treated cells, the Fas gene mRNA expression significantly increased with $1000 \mu \mathrm{M}$ of LEN by almost 3.663 folds in comparison with the control cells $(\mathrm{P}<0.05)$. This gene was overexpressed with a combination of $1000 \mu \mathrm{M}$ of LEN and $100 \mu \mathrm{M}$ of DEX by almost 1.825 folds compared to the control cells (Figure 3A). The results showed that the mRNA expression of the FasL gene significantly decreased (by about 0.072 folds) with $1000 \mu \mathrm{M}$ of LEN and $100 \mu \mathrm{M}$ of DEX compared to the control cells $(\mathrm{P}<0.05)$ (Figure 3B).

\subsubsection{Bax Gene}

The Bax gene mRNA expression significantly increased (by about 5.629 folds) in the cells treated with $1000 \mu \mathrm{M}$ of LEN for 48 hours compared to the controls $(\mathrm{P}<0.05)$. By using DEX at $1000 \mu \mathrm{M}$ for 48 hours, the Bax gene mRNA expression significantly increased (by about 1.795 folds) compared to the controls $(\mathrm{P}<0.05)$. Also, the Bax gene mRNA 

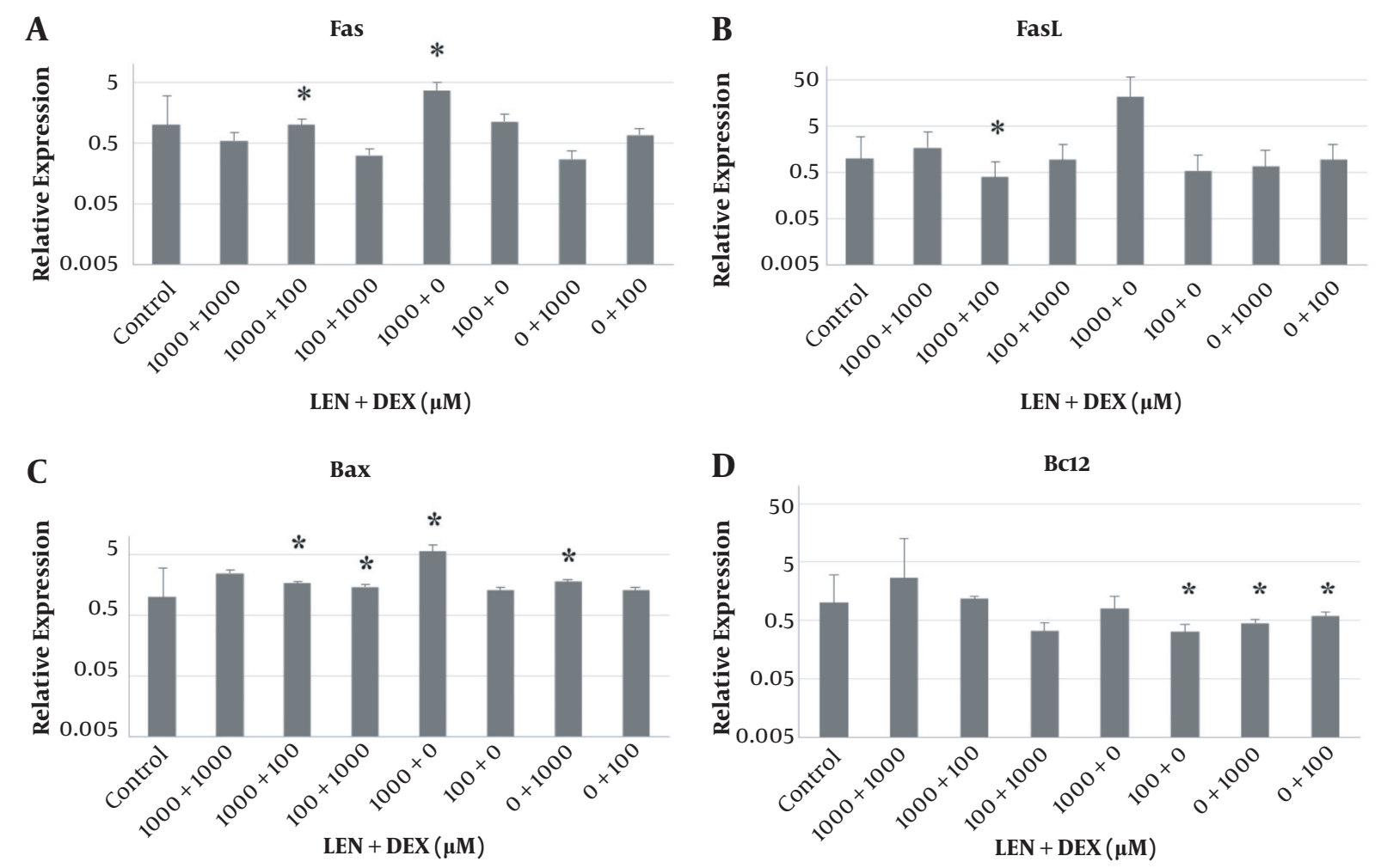

Figure 3. The effects of LEN and DEX on apoptosis-related mRNA expression in the human colorectal cancer HT-29 cell line. (A) Fas mRNA expression; (B) FasL mRNA expression; (C) Bax mRNA expression; (D) Bcl2 mRNA expression. The mRNA expression was investigated using qRT-PCR assay; the GAPDH gene was used as an internal control. Values are presented as mean and standard deviation (SD) of the expression levels of genes ( ${ }^{*} \mathrm{~A}$ significant increase or decrease in gene expression at $\mathrm{P}<0.05$ compared to the control untreated group). All experiments were performed in duplicate.

expression significantly increased (by about 1.68 folds) via treatment with a combination of $1000 \mu \mathrm{M}$ of LEN and 100 $\mu \mathrm{M}$ of $\operatorname{DEX}(\mathrm{P}<0.05)$. Also, when using $100 \mu \mathrm{M}$ of LEN plus $1000 \mu \mathrm{M}$ of DEX, significant upregulation of the Bax gene was observed (by almost 1.481 folds), compared to the control cells $(\mathrm{P}<0.05)$ (Figure 3C).

\subsubsection{Bcl2 Gene}

A significant reduction was observed (by about 0.323 folds) in the Bcl2 gene mRNA expression in the cells treated with $100 \mu \mathrm{M}$ of LEN compared to the control cells ( $\mathrm{P}<$ 0.05). Individually, $1000 \mu \mathrm{M}$ and $100 \mu \mathrm{M}$ of DEX (by about 0.453 and 0.595 folds, respectively) led to a significant decrease in the $B c l 2$ gene mRNA expression compared to the controls $(\mathrm{P}<0.05)$. However, by using a combination of these 2 drugs, the level of $B c l 2$ gene mRNA expression significantly increased (by about 1.186 folds) in comparison with the control cells $(\mathrm{P}<0.05)$ (Figure 3D).

Figure 4 illustrates the results of agarose gel electrophoresis. The length of Fas and FasL PCR products was 110 and $241 \mathrm{bp}$, respectively, and the length of Bax and BcL2
PCR products was 104 and 187 bp, respectively.

\section{Discussion}

Tumor cells can be resistant to apoptosis by the expression of anti-apoptotic proteins and downregulation or mutation of pro-apoptotic proteins (15). According to immunohistochemistry studies, the Fas gene expression is diminished in a subpopulation of colorectal tumors (16). The present study investigated the anti-proliferative effects of LEN and DEX on the HT-29 cell line. In this regard, a previous study showed that thalidomide and its analogs induced apoptosis and exerted cytotoxic effects on the HepG2 and MCF-7 cell lines (17). Another study reported the anti-tumor activities of thalidomide analogs against the HCT-116 and Hep-G2 cell lines (18).

Moreover, Mitsiades et al. (19) suggested that LEN was a more potent apoptosis activator than thalidomide. Other studies found that LEN induced growth inhibitory effects in several NSCLC cell lines in a concentration-dependent manner and regulated the expression of several genes (20). 
A
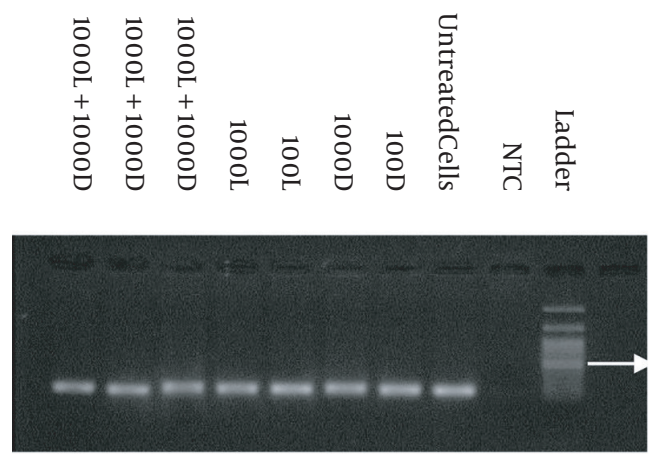

C
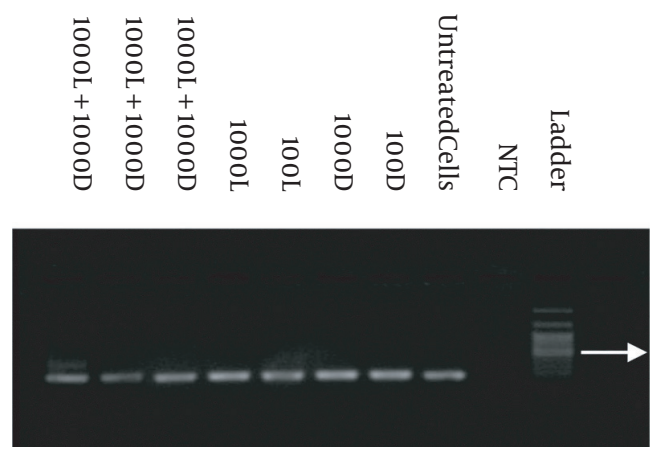

$500 \mathrm{bp}$
B
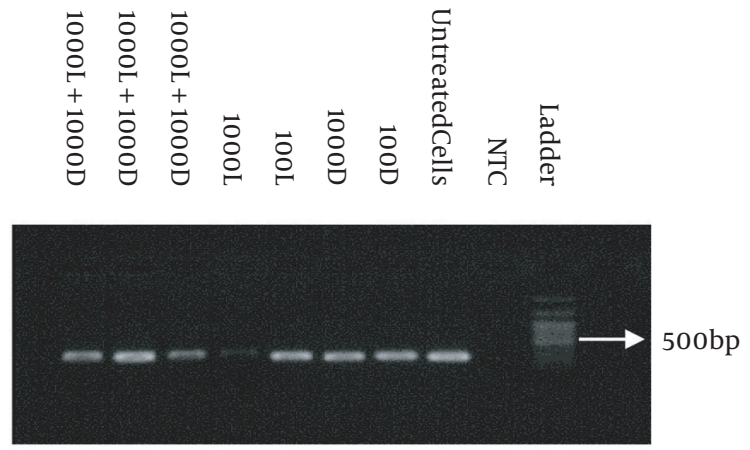

D
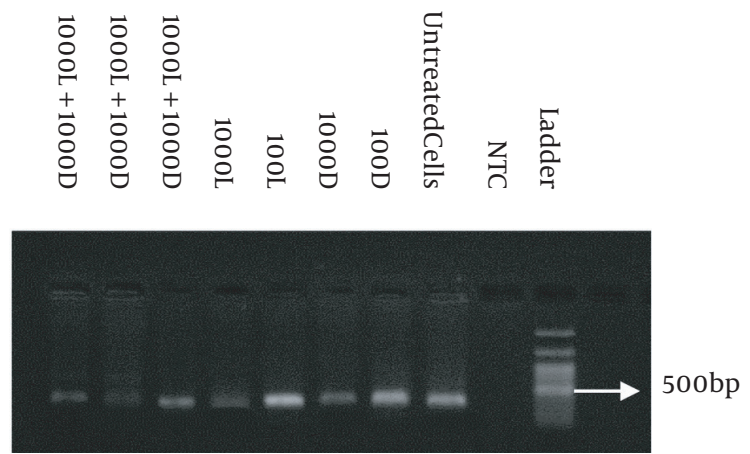

Figure 4. Agarose gel electrophoresis of PCR products. (A) Fas gene; (B) FasL gene; (C) Bax gene; and (D) Bcl2 gene. NTC: Negative control (without template); Ladder: 100 bp (SMOBIO DM2300). L: LEN, D: DEX (L and D concentrations are expressed as $\mu \mathrm{M}$ ).

According to the present results, although only Fas and Bax mRNA expression increased via treatment with $1000 \mu \mathrm{M}$ of LEN in the HT-29 cell line, compared to untreated cells, LEN had no anti-proliferative effects on the HT-29 cell line at a concentration of $1000 \mu \mathrm{M}$ independently. Also, no growth inhibitory effect was observed at different concentrations of LEN independently.

The current results showed that DEX induced cell death in a dose- and time-dependent manner. The MTT assays showed that treatment with DEX at $1000 \mu \mathrm{M}$ significantly inhibited the growth of treated HT-29 cells compared to untreated cells $(\mathrm{P}<0.05)$. The cell viability was 68\%, 50\%, and $24 \%$ after 24,48 , and 72 hours, respectively, and the $\mathrm{IC}_{50}$ was $1000 \mu \mathrm{M}$ after 48 hours of incubation. DEX alone at $1000 \mu \mathrm{M}$ caused a reduction only in the $B c l 2$ gene mRNA expression. Moreover, we used a combination of LEN with DEX against the HT-29 cell line. The cell viability was 61\%, $35 \%$, and $15 \%$ after 24,48 , and 72 hours, respectively. The combination of LEN $(1000 \mu \mathrm{M})$ with DEX $(100 \mu \mathrm{M})$ showed greater anti-proliferative effects compared to LEN and DEX alone.
Based on the present results, LEN in combination with DEX synergistically induced apoptosis through extrinsic and intrinsic pathways in the HT-29 cell line. Therefore, in the treated cells, the expression of Fas and FasL genes was upregulated and downregulated, respectively. Besides, the $B c l 2$ gene expression, as an anti-apoptotic gene, was upregulated with this combination. However, the Bax gene expression, as a pro-apoptotic gene, was upregulated more than the Bcl2 gene in the HT-29 cell line compared to untreated cells. In this regard, previous studies have been reported that the expression of the FasL gene gradually increased during progression from adenoma to colorectal carcinoma $(21,22)$; the downregulation of Fas receptors in colon cancer cells conferred resistance to apoptosis (21).

Moreover, consistent with our results, a previous study showed that the combination of LEN with DEX only synergistically activated mitochondria-mediated apoptosis. Nonetheless, in the present study, this combination could activate both extrinsic and intrinsic apoptotic pathways in the HT-29 cell line (23). Another study showed that LEN inhibited the proliferation of multiple myeloma and plasma 
cell leukemia cell lines, which was enhanced by DEX (24).

\subsection{Conclusions}

The present study is the first in vitro study, showing the anti-proliferative effects of LEN and DEX individually and in combination on the colorectal cancer HT-29 cell line by inducing apoptosis and affecting apoptosis genes. The cytotoxic effect of LEN plus DEX was more significant than each medication used individually. By studying the molecular mechanisms of anti-proliferative effects by examining Fas, FasL, Bax, and Bcl2 gene expression, we found that the combination of these 2 medications could induce cell death via activation of extrinsic and intrinsic apoptotic pathways. However, the combination of LEN with DEX was the most effective apoptotic drug compared to LEN and DEX alone. Therefore, this combination can be a promising treatment for CRC in the future. Further in vivo studies are needed for a better understanding of the anti-proliferative effects of this combination treatment.

\section{Acknowledgments}

This study was extracted from a Master's thesis by P.H.S.

\section{Footnotes}

Authors' Contribution: H.Sh.P. conducted the laboratory work. H.Sh.P. and Sh.M. conducted the molecular experiments and RT-qPCR. F.F. contributed to the study design, data collection and analysis, manuscript draft, and statistical analysis. All authors revised the manuscript, approved the final version for submission, and participated in its finalization.

Conflict of Interests: None.

Funding/Support: None.

\section{References}

1. Tariq K, Ghias K. Colorectal cancer carcinogenesis: a review of mechanisms. Cancer Biol Med. 2016;13(1):120-35. doi: 10.28092/j.issn.20953941.2015.0103. [PubMed: 27144067]. [PubMed Central: PMC4850121].

2. Arnold M, Sierra MS, Laversanne M, Soerjomataram I, Jemal A, Bray F. Global patterns and trends in colorectal cancer incidence and mortality. Gut. 2017;66(4):683-91. doi:10.1136/gutjnl-2015-310912. [PubMed: 26818619].

3. Wolf AMD, Fontham ETH, Church TR, Flowers CR, Guerra CE, LaMonte SJ, et al. Colorectal cancer screening for average-risk adults: 2018 guideline update from the American Cancer Society. CA Cancer J Clin. 2018;68(4):250-81. doi: 10.3322/caac.21457. [PubMed: 29846947].

4. Abraha AM, Ketema EB. Apoptotic pathways as a therapeutic target for colorectal cancer treatment. World J Gastrointest Oncol. 2016;8(8):58391. doi: 10.4251/wjgo.v8.i8.583. [PubMed: 27574550]. [PubMed Central: PMC4980648].
5. Goldar S, Khaniani MS, Derakhshan SM, Baradaran B. Molecular mechanisms of apoptosis and roles in cancer development and treatment. Asian Pac J Cancer Prev. 2015;16(6):2129-44. doi: 10.7314/apjcp.2015.16.6.2129. [PubMed: 25824729].

6. Letai A. Apoptosis and Cancer. Annual Review of Cancer Biology. 2017;1(1):275-94. doi:10.1146/annurev-cancerbio-050216-121933.

7. Jan R, Chaudhry GE. Understanding apoptosis and apoptotic pathways targeted cancer therapeutics. Adv Pharm Bull. 2019;9(2):20518. doi: 10.15171/apb.2019.024. [PubMed: 31380246]. [PubMed Central: PMC6664112].

8. Zhu J, Petit PF, Van den Eynde BJ. Apoptosis of tumor-infiltrating T lymphocytes: a new immune checkpoint mechanism. Cancer Immunol Immunother. 2019;68(5):835-47. doi: 10.1007/s00262-018-2269-y. [PubMed: 30406374].

9. Kim HJ, Bae SC. Histone deacetylase inhibitors: molecular mechanisms of action and clinical trials as anti-cancer drugs. Am JTransl Res. 2011;3(2):166-79. [PubMed: 21416059]. [PubMed Central: PMC3056563].

10. Miller CP, Singh MM, Rivera-Del Valle N, Manton CA, Chandra J. Therapeutic strategies to enhance the anticancer efficacy of histone deacetylase inhibitors. J Biomed Biotechnol. 2011;2011:514261. doi: 10.1155/2011/514261. [PubMed: 21765634]. [PubMed Central: PMC3134392].

11. Quach H, Ritchie D, Stewart AK, Neeson P, Harrison S, Smyth MJ, et al. Mechanism of action of immunomodulatory drugs (IMiDS) in multiple myeloma. Leukemia. 2010;24(1):22-32. doi: 10.1038/leu.2009.236. [PubMed: 19907437]. [PubMed Central: PMC3922408].

12. Shinji C, Maeda S, Imai K, Yoshida M, Hashimoto Y, Miyachi H. Design, synthesis, and evaluation of cyclic amide/imide-bearing hydroxamic acid derivatives as class-selective histone deacetylase (HDAC) inhibitors. Bioorg Med Chem. 2006;14(22):7625-51. doi: 10.1016/j.bmc.2006.07.008. [PubMed:16877001].

13. Gupta SC, Sung B, Prasad S, Webb LJ, Aggarwal BB. Cancer drug discovery by repurposing: teaching new tricks to old dogs. Trends Pharmacol Sci. 2013;34(9):508-17. doi: 10.1016/j.tips.2013.06.005. [PubMed: 23928289].

14. Chanan-Khan AA, Cheson BD. Lenalidomide for the treatment of B-cell malignancies. J Clin Oncol. 2008;26(9):1544-52. doi: 10.1200/JCO.2007.14.5367. [PubMed: 18285605].

15. Campbell KJ, Tait SWG. Targeting BCL-2 regulated apoptosis in cancer. Open Biol. 2018;8(5). doi: 10.1098/rsob.180002. [PubMed: 29769323]. [PubMed Central: PMC5990650].

16. Langers I, Renoux VM, Thiry M, Delvenne P, Jacobs N. Natural killer cells: Role in local tumor growth and metastasis. Biologics. 2012;6:7382. doi: 10.2147/BTT.S23976. [PubMed: 22532775]. [PubMed Central: PMC3333822].

17. Talaat R, El-Sayed W, Agwa H, Gamal-Eldeen A, Moawia S, Zahran M. Novel thalidomide analogs: Anti-angiogenic and apoptotic effects on Hep-G2 and MCF-7 cancer cell lines. Biomedicine \& Aging Pathology. 2014;4(3):179-89. doi:10.1016/j.biomag.2014.03.002.

18. Zahran MA, Gamal-Eldeen AM, El-Hussieny EA, Agwa HS. Thalidomide dithiocarbamate and dithioate derivatives induce apoptosis through inhibition of histone deacetylases and induction of caspases. Journal of Genetic Engineering and Biotechnology. 2014;12(1):6570. doi: 10.1016/j.jgeb.2014.03.003.

19. Mitsiades N, Mitsiades CS, Poulaki V, Chauhan D, Richardson PG, Hideshima T, et al. Apoptotic signaling induced by immunomodulatory thalidomide analogs in human multiple myeloma cells: Therapeutic implications. Blood. 2002;99(12):4525-30. doi: 10.1182/blood.v99.12.4525. [PubMed: 12036884].

20. Kim K, An S, Cha HJ, Choi YM, Choi SJ, An IS, et al. Lenalidomide induces apoptosis and alters gene expression in non-small cell lung cancer cells. Oncol Lett. 2013;5(2):588-92. doi: 10.3892/ol.2012.1054. [PubMed: 23420263]. [PubMed Central: PMC3573063]. 
21. O'Connell J, Bennett MW, O'Sullivan GC, Roche D, Kelly J, Collins K, et al. Fas ligand expression in primary colon adenocarcinomas: evidence that the Fas counterattack is a prevalent mechanism of immune evasion in human colon cancer.J Pathol.1998;186(3):240-6. doi: 10.1002/(sici)1096-9896(199811)186:3<240::Aid-path173>3.0.Co;2-l.

22. Bennett MW, O'Connell J, Houston A, Kelly J, O'Sullivan GC, Collins $\mathrm{JK}$, et al. Fas ligand upregulation is an early event in colonic carcinogenesis.JClin Pathol.2001;54(8):598-604. doi:10.1136/jcp.54.8.598. [PubMed: 11477113]. [PubMed Central: PMC1731496].

23. Qian Z, Zhang L, Cai Z, Sun L, Wang H, Yi Q, et al. Lenalidomide synergizes with dexamethasone to induce growth arrest and apoptosis of mantle cell lymphoma cells in vitro and in vivo. Leuk Res. 2011;35(3):380-6. doi: 10.1016/j.leukres.2010.09.027. [PubMed: 21047686].

24. Gandhi AK, Kang J, Capone L, Parton A, Wu L, Zhang LH, et al. Dexamethasone synergizes with lenalidomide to inhibit multiple myeloma tumor growth, but reduces lenalidomide-induced immunomodulation of T and NK cell function. Curr Cancer Drug Targets. 2010;10(2):15567. doi: 10.2174/156800910791054239. [PubMed: 20088798]. 